\title{
Insight
}

\section{Beyond Baselines: Rethinking Priorities for Ocean Conservation}

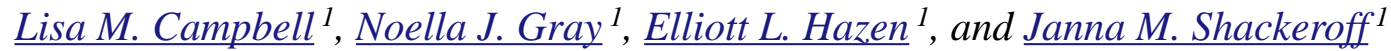

\begin{abstract}
In 1995, Daniel Pauly identified a "shifting baselines syndrome" (SBS). Pauly was concerned that scientists measure ecosystem change against their personal recollections of the past and, based on this decidedly short-term view, mismanage fish stocks because they tolerate gradual and incremental elimination of species and set inappropriate recovery goals. As a concept, SBS is simple to grasp and its logic is compelling. Much current work in marine historical ecology is rationalized in part as a means of combating SBS, and the term has also resonated outside of the academy with environmental advocacy groups. Although we recognize both conceptual and operational merit in SBS, we believe that the ultimate impact of SBS on ocean management will be limited by some underlying and interrelated problematic assumptions about ecology and human-environment relations, and the prescriptions that these assumptions support. In this paper, we trace both assumptions and prescriptions through key works in the SBS literature and interrogate them via ecological and social science theory and research. We argue that an expanded discussion of SBS is needed, one that engages a broader range of social scientists, ecologists, and resource users, and that explicitly recognizes the value judgments inherent in deciding both what past ecosystems looked like and whether or not and how we might reconstruct them.
\end{abstract}

Key Words: baselines; human-environment relations; interdisciplinary research; marine historical ecology

\section{INTRODUCTION}

In 1995, Daniel Pauly identified a shifting baselines syndrome (SBS), where "each generation of fisheries scientists accepts as a baseline the stock size and species composition that occurred at the beginning of their careers, and uses this to evaluate changes" (Pauly 1995: 430). Pauly was concerned that scientists mismanage fish stocks because they tolerate gradual and incremental elimination of species, set inappropriate recovery goals, and use the wrong reference points when calculating economic losses due to overfishing. The SBS is simple to grasp and its logic compelling. These features, combined with general concerns about widespread overfishing (Worm et al. 2006, Food and Agriculture Organization (FAO) 2007), help explain SBS's popularity. As of 1 November 2008, the original one-page postscript had been cited 201 times according to the Web of Science, part of Thomson Reuters' citation database ISI Web of Knowledge. The SBS has become an important justification for work in marine historical ecology
(Christensen et al. 2003, Baum and Myers 2004, Rosenberg et al. 2005, Pinnegar and Engelhard 2008).

In this paper, we consider the conceptual and operational merit of SBS and some of its problematic assumptions. These assumptions relate to ecology and human-environment relations and can be seen in SBS and prescriptions arising from it. We focus our analysis on key works by: Daniel Pauly, who coined the term; Jeremy Jackson, whose marine historical ecology of the Caribbean is a widely recognized attempt to reconstruct baselines; and Tony Pitcher, who operationalizes a response to SBS using reconstructed ecological pasts to model potential futures. We use the term SBS to refer to both the concept and the work it has inspired in marine historical ecology. We recognize that not all marine historical ecologists adopt the assumptions underlying SBS, but we use these terms somewhat interchangeably for the sake of simplicity. We conclude our analysis by suggesting ways to overcome limitations and capitalize on the 
merits of SBS, all toward the goal of realizing improved oceans management. We also discuss the ways in which our analysis of SBS reflects some contemporary debates about the role of science in informing policies for resource management.

We note from the outset that what we are calling marine historical ecology - a field of study that uses historical data sets and ecological modeling to describe what marine ecosystems might have looked like in the past-is distinct from historical ecology in the terrestrial realm (e.g., Crumley 1994, Bale 1998). The two fields evolved concurrently and both are interested in historical conditions and human impacts on the environment, but there has been little interaction between them. With few exceptions (e.g., Kirch and Hunt 1997), historical ecologists have paid scant attention to ocean systems (van Sittert 2003, Bolster 2006), and none of the marine historical ecology papers reviewed here cite works from historical ecology more generally. This disconnect is at least in part due to marine historical ecology's connection with the natural sciences, whereas historical ecology arose primarily from the social sciences.

\section{CONCEPTUAL AND OPERATIONAL MERIT}

The SBS helps us to envision alternative ecosystems and provides compelling evidence of large-scale and widespread changes to ocean ecosystem structure and function (Pinnegar and Engelhard 2008). In the Caribbean, Jackson and colleagues paint an extraordinary picture of marine life from as few as 30 to as many as 125000 years before present (Jackson 1997, 2001, Jackson et al. 2001). For example, Jackson (1997) extrapolates a Caribbean carrying capacity of 660 million green turtles; although this was later revised downward to 16-33 million (Jackson et al. 2001), it remains almost unfathomable given current population estimates of $<200000$ adult female green turtles in the Caribbean, with the largest population (at Tortuguero, Costa Rica) having $<50000$ nesting per year (Troëg and Rankin 2005).

Conceptually, SBS challenges our perceptions of change and lends itself well to visual representation. Images of past (pristine) and contemporary (degraded) ecosystems are useful for conservationists wishing to illustrate the impacts of humans on ecosystems (e.g., http://www.shiftingbaselines.org/ news/photocont.html). The concept's accessibility and simplicity have broadened its appeal beyond the academy and SBS is used as a tool for environmental advocacy; "Shifting Baselines" is a self-proclaimed partnership between "ocean conservation and Hollywood" and at its Hollywood "oceans night," both Pauly and Jackson appeared on the blue carpet as ocean celebrities (see http://www.shiftingbaselines. org/news/news11.html).

Operationally, SBS may foster interdisciplinary collaborations. Pauly (1995) argues that in order to reconstruct baselines, historical data-including those gained from indigenous or traditional ecological knowledge-are required, as are interdisciplinary approaches to collecting them. Pauly (1995) [and later Jackson (1997)] calls on ecologists to appreciate data sets that might not pass the "usual standards" in experimental biological science. Documentary data (e.g., from fishing logs or tax records) have featured prominently in marine historical ecology, but Pinnegar and Engelhard (2008) include art and literature as potential data sources. The emphasis on interdisciplinarity extends beyond data collection, as "rebuilding aquatic ecosystems is inherently interdisciplinary" (Pitcher and Pauly 1998: 313). Leaving aside for now the challenges of integrating different types of knowledge, if concern for SBS leads to recognition of different disciplines and data types among ecologists, it may move general attempts at interdisciplinary research forward. Although widely promoted as critical to conservation, interdisciplinary research is hampered on a number of fronts, including epistemological ones that distinguish between social and natural sciences and that relate to definitions of what constitutes data and science (Campbell 2005, Adams 2007).

Although SBS may improve interdisciplinary collaboration, one ambitious undertaking, the History of Marine Animal Populations (HMAP) project, has been criticized for its engagement with historical research. HMAP, under the auspices of the Census of Marine Life, is a collaboration of over 100 scientists and uses data from historical archives to analyze "marine population data before and after human impacts on the ocean became significant" ( http://www.hmapcoml.org/). However, according to van Sittert (2005), a one-time leader on the HMAP Southwest Africa Shelf project, HMAP's "primary focus on quantification" and modeling does not allow for adequate attention to historical context. It has "rendered the humanists the data serfs 
of 'scientist' model lords," and fails to recognize developments in historical inquiry that emphasize "science and nature as "context-dependent cultural constructs"' (van Sittert 2005: 107). Bolster (2006), another HMAP historian, credits HMAP scientists as some of the few willing to embrace unconventional data. Nevertheless, Bolster (2006: 572) raises many "deeper historical questions" about the "ecological and cultural transformations that have cast the twenty-first-century ocean as vulnerable rather than eternal" and that are not addressed in HMAP.

The HMAP's experience is not surprising; interdisciplinary collaboration across natural and social sciences has generally been more successful when types of data and analysis are similar, i.e., quantitative (Redclift 1998, Campbell 2003). Regardless, the potential for SBS to promote more diverse and meaningful engagements between natural and social sciences remains.

\section{ECOLOGICAL ASSUMPTIONS}

Three key ecological assumptions underlie SBS. The first is that a natural baseline exists and can be identified and agreed upon. In the SBS literature, baselines are generally defined as existing prior to human exploitation, but with varied interpretations of what this means. Pitcher and Pauly (1998: 312) define primal states as "those existing before humans used large-scale harvesting." Primal systems in some parts of the world existed "thousands of years BP, in others only as little as 50 years BP" (Pitcher and Pauly 1998: 325). Pinnegar and Engelhard (2008) suggest even artisanal fishing thousands of years ago degraded ecosystems, and Pitcher (2005) identifies ecosystems in the late Pleistocene post-glacial era (pre-modern human) as a pristine baseline against which change could be assessed, even if restoring such ecosystems is unlikely. In contrast, Bjorndal and Bolten (2003) argue for restoring green sea turtles in the Caribbean to levels believed to match those found in prehuman or pre-historic times. The point here is that ecologists make judgments about where to set baselines, suggesting there is nothing "natural" or self-evident about them.

The second ecological assumption is that, once agreed upon, baselines can be described accurately. This is problematic for a number of reasons. First, much existing data on the marine environment are species specific and related to those species that are valuable and accessible. Thus, historical analyses have focused on species such as cod (Gadus spp.; Rosenberg et al. 2005), grouper (Mycteroperca jordani; Sánz-Arroyo et al. 2005), and turtles (Chelonia mydas; Jackson 1997), rather than on ecosystems. Second, even where good data exist and describe an organism's performance (e.g., reproductive rates, mortality, consumption), this is in contemporary ecosystems. For example, Jackson (1997) first extrapolated a baseline population of 660 million green turtles in the Caribbean based on Bjorndal's (1982) assessment of the carrying capacity of Thalassia testudinum (or turtle grass), one staple of an adult green turtle's diet. The number was revised downward (Jackson et al. 2001) after estimates of $T$. testudinum productivity were recalculated (Bjorndal et al. 2000). As this example illustrates, our understanding of ocean ecosystems is evolving; the challenge of describing past ecosystems based on an incomplete understanding of contemporary ones is considerable. Third, although mass balance models used by ecologists, such as ECOPATH and ECOSIM, use Bayesian statistics to incorporate sources of uncertainty (Pauly et al. 2000), they rely on the accuracy and completeness of inputs (Pinnegar and Engelhard 2008). Pitcher (2005) acknowledges the difficulty in obtaining time series data that adequately represent change in fishing technology and practice, and thus the necessity of relying on ecosystem snapshots. In addition, mass balance models simplify ecological processes and, in doing so, fail to incorporate potential structural changes that impede restoration, such as habitat change, regime shifts, and genetic drift. Thus, although such models undoubtedly improve our ability to describe past ecosystems, their results remain estimates rather than certainties.

The third ecological assumption is that once described, baselines can be restored, a kind of "there and back again" ecology. [Pitcher (2005) names his restoration ecology "back-to-the-future," or BTTF.] Both ecological theory and case study evidence pose problems for this assumption. Theoretically, the vision of a once-balanced ecosystem contrasts with ecosystems described by Berkes and Folke (1998: 12) as "complex, non-linear, multi-equilibrium and self-organizing... permeated by uncertainty and discontinuities." Holling et al. (1998: 354) contend that a "linear, equilibrium-centered view of nature no longer fits the evidence." More specifically, resilience theory suggests that ecosystems can 
occupy multiple stable states and can undergo dramatic regime shifts, due to both anthropogenic and non-anthropogenic forcers (Holling 1973, Scheffer and Carpenter 2003, Folke et al. 2004), with climate playing an important role (Pinnegar and Engelhard 2008). For example, in the Pacific, Chavez et al. (2003) identify anchovy and sardine regimes that alternate according to fluctuations in sea surface temperature. Other research suggests that unidirectional regime shifts can also occur. Carscadden et al. (2002) examine the relationship between sea birds and capelin (Mallotus villosus), and the regime shift that occurred due to belowaverage sea temperatures in the early 1990s. Contrary to expectations, this new regime persisted after water temperatures returned to normal. These examples belie the existence of a single, stable (or "natural") state for ecosystems.

When change is directly linked to human activity, eliminating such activity may fail to reestablish past ecosystems. The Canadian East Coast cod fishery provides such an example. A temporary fishing moratorium was instituted in 1992, to allow "the spawning biomass to recover quickly to its longterm average." The recovery remains elusive, and the moratorium (actually a series of spatially and temporally explicit moratoria) remains in effect. By 2002, cod had shown no real signs of improvement (Canadian Science Advisory Secretariat 2006). Frank et al. (2005) describe trophic cascades associated with overfishing in the region, but link failed recovery to physical environmental changes (e.g., temperature and stratification); "whether the recent ecosystem changes are reversible is an open question" (Frank et al. 2005: 1622).

Pitcher (2005) anticipates the critique of this third assumption, labeling it the "ecosystems do not rewind" argument. Although Pitcher acknowledges that there may be cases where reversal is not possible, he counters with examples of fisheries that do rewind if given the opportunity. We do not question this assertion, but the ability to return to a prior state, even if it can be identified, cannot be assumed.

\section{ASSUMPTIONS ABOUT HUMAN- ENVIRONMENT RELATIONS}

The key assumption about human-environment relations underlying the baselines concept is that humans are outside of nature. This is reflected in the definitions of baselines as pre-human intervention, and in the emphasis on restoring "natural" baselines. The conceptual separation of nature from culture in Western society, and the consequences of this, is a topic that has received much attention in the social sciences and humanities (e.g., Cronon 1995, Castree and Braun 2001). Terrestrial ecologists have been challenged on and have responded to this issue, as reflected in the parks vs. people debate [and the debate about the debate! See Brockington et al. (2006) and Redford et al. (2006)]. Marine ecologists and conservationists can more easily place humans outside of nature, both for the obvious reason that humans cannot breathe unassisted in water and because the ocean is often characterized as a vast open-access resource where the tragedy of the commons plays out (Jackson 1995, King 2005). The view of humans as outside of nature, and of oceans as unpeopled, can be contrasted with a humans-in-nature view promoted by Berkes and Folke (1998) and Berkes et al. (2003) in describing social-ecological systems (a concept we return to later).

There are several consequences arising from the separation of humans from marine nature. First, because humans are "naturally" outside of marine nature, when they do enter ecological equations, they are a problem, serving as top-down (e.g., through fishing) or bottom-up (e.g., through direct and indirect pollution) forcers, or as habitat modifiers (e.g., via trawling and dredging effects). More specifically in SBS, fisheries are the problem, reflecting both the etymology of SBS (Pauly is a fisheries ecologist) and that most long-term data available come from fisheries. Although we do not question what is now global concern with declining fish stocks, we do suggest that the emphasis in SBS on human drivers of change overlooks the role of non-anthropogenic variability in marine ecosystems as described above, and (more importantly) reinforces a static vision of nature in equilibrium prior to human exploitation, a nature to which things are done. This belies the complexity of both ecosystems and social systems, and the links between them. Objectifying humans as exploiters of and separate from nature also narrows the scope of research to one aspect of human-environmental relations, suggesting that regardless of human agency, all humans behave in the same way. This overlooks the ways in which individuals, groups, or institutions, not only degrade, but also conserve and restore oceans. 
Second, because humans are excluded from marine nature, ecological baselines become the only ones of interest (and marine ecologists the authorities for describing them). Although Pauly, Pitcher, and Jackson all recognize that society will have to make some "tough choices" when rebuilding baselines, they assume a human-free baseline is the right one, and any movement away from this is a compromise. All three writers deny any desire to "turn back the clock" on human development. Pitcher and Pauly (1998: 325) state that "we would not necessarily wish to, nor be able to, restore things to their Pleistocene levels," a goal they deem "clearly unrealistic." Jackson (1997: S24) states that he is "not going to make some romantic appeal to set back the clock, nor propose draconian scenarios that ignore the realities of inexorable human population growth and underdevelopment." Pitcher (2005: 118) states that that he does not "aim to bring back the human social conditions of the past." Nevertheless, there is little or no discussion of what human societies looked like in the past, or will have to look like in the future, to restore the baselines they identify. Reference is made to the necessity of fewer fishers and smaller fleets, and to economic benefits accrued through more productive fisheries (e.g., Pauly et al. 2002, Pitcher 2001, 2005), but costs and benefits are detailed at the aggregate level and fishers are contextless, without nationality, gender, community, society, or culture.

\section{PROBLEMATIC PRESCRIPTIONS}

The combination of assumptions about ecology and human-environment relations supports a series of prescriptions, the most common of which is the call to abandon sustainability as a management goal; managers should instead work to reestablish historic baselines and be rewarded for doing so (Jackson 2001, Pitcher 2001, Pauly et al. 2002). The first step in restoration is reducing fishing and sometimes eliminating it. Jackson (2001: 5416), for example, describes the logic of "simply stopping fishing. There is no rational scientific basis to continue fishing of wild stocks along the Atlantic coast of North America or in the Caribbean for the foreseeable future." Less extreme reductions range according to fishery and location; Pauly (2006) suggests the number of fishing vessels will have to be reduced by a factor of three in many places, and Pauly et al. (2002: 694) call for a "huge reduction of fishing effort." Reductions can be accomplished by decommissioning fleets (Pauly et al. 2002), eliminating subsidies (Pauly 2006), targeting luxury species for consumption by tourists (Jackson 1997) or top predators for recreational fishing (Picher and Pauly 1998), and establishing marine protected areas (Pitcher and Pauly 1998, Pauly et al. 2002, Pauly 2006).

These prescriptions are problematic for several reasons. First, all of the means for pursuing recovery have been critiqued for their social and economic impacts, as well as environmental ones (e.g., marine protected areas (MPAs): Christie et al. 2003, Christie 2004). Although any one of these measures may be implemented effectively, none is a panacea for success (however measured). Without detailed understanding of the consequences of such prescriptions for both people and environments in specific contexts, their implementation may flounder and negative effects can result (e.g., a marine reserve that is fished illegally or an individual transferable quota (ITQ) system that leads to increased discarding). There needs to be greater attention to the complexity of such measures, both their benefits and their costs.

Second, in promoting particular management interventions, SBS writers focus on (potential) economic gains. Jackson et al. (2001: 636) describe "the extraordinary magnitude of economic resources that are retrievable if we are willing to act on the basis of historical knowledge." Pitcher and Pauly (1998: 321-323) outline socioeconomic alternatives (that are really economic alternatives, based on gross aggregate economic value), and argue that rebuilding will be more economically beneficial than other options. Pauly et al. (2002) suggest fishers who are forced to stop fishing be compensated by a tax posed on those who continue to do so. These arguments are premised implicitly on neoclassical economic theory that poses fishers as profit-maximizing individuals driven by rational choice, and ignore the literature that challenges this characterization (e.g., Maurstad 2000, St. Martin 2001, 2005a, Pollnac and Poggie 2006). Although fishers often do behave in ways that conform to neoclassical expectations, these are not the only ways they behave. Furthermore, the focus on economics reflects a dominant managerial paradigm, one that is itself implicated in the collapse of ocean resources (Berkes and Folke 1998) and of fisheries in particular, where bioeconomic modeling has been the norm (Wilson 2006). Although there are calls of interdisciplinary work in SBS, economics appears to be the other discipline of choice when moving from description to action. 
Third, if our critique of SBS is correct (or even partially so), then the goal of pursuing recovery of natural baselines is questionable both in the normative and practical sense, ecologically and otherwise. We do not oppose the identification of recovery goals, but such goals are neither selfevident nor "natural." Rather, decisions about the appropriate baseline to target and mechanisms for pursuing it will involve value judgments. Following Lélé and Norgaard (1996) in their critique of sustainability, we suggest that values need to be explicitly acknowledged when setting priorities for ocean conservation. The values SBS writers espouse regarding pristine ecosystems are one set of values that may inform priority setting, but not the only ones. Other stakeholders will promote other values, and these need to be recognized. There is a practical need for such recognition; an argument that rests on the notion that oceans are unpeopled and that characterizes fishers and other resource users as unnatural intrusions will do little to engage these stakeholders. But calls for recognition of competing values are also philosophical and reflect debates about the interactions of science, values, and advocacy that are taking place both in general (e.g., in conservation biology, see Lackey 2007) and in fisheries management specifically (e.g., Jentoft 2006), a point we return to in the conclusion.

Finally, the SBS literature mostly ignores the role of fishers and other resource users in the formation, uptake, monitoring, and enforcement of policy change. This oversight runs counter to much work regarding the importance of local participation for successful oceans management (Johannes et al. 2000, Berkes 2003) and the vast and growing literature on the potential for fisheries comanagement (Wilson et al. 2003, Carlsson and Berkes 2005). More generally, it bypasses the opportunity to nurture the diversity of uses and knowledge systems, including those of fishers, the understanding of which might enhance the capacity of marine systems to adapt to change (Berkes et al. 2003, Olsson et al. 2004). Although non-traditional data sources are recognized in SBS, indigenous or traditional ecological knowledge (TEK) is privileged whereas local ecological knowledge derived from fishers or other users is rarely mentioned. Pitcher (2005) is an exception, and he scopes out a role for both TEK holders and more general stakeholders in his nine-step BTTF policymaking process. However, his treatment of both participation and TEK is problematic. Regarding participation, in a list of nine criteria ranked hierarchically, "participatory vetting of fisheries" ranks seventh and is constrained by the fulfillment of a number of earlier criteria. Furthermore, participation occurs in a political vacuum, with no consideration of the power at work in participatory activities (Leach et al. 2005). This is a critical oversight, especially given the reliance of BTTF on computer modeling through ECOSIM and ECOPATH, the actual operations of which will be understood by few individuals participating. Regarding TEK, Pitcher gives greater weight to aboriginal fishers (the third of nine criteria), but argues for its cross-validation. Although he recognizes that matching TEK with scientific knowledge is difficult, he argues that this can be accomplished by "breaking down the problem into simple choices; for example, presence and absence, place and time" (Pitcher 2001: 609). This view of TEK overlooks a growing literature related both to its nature and to methodological and ethical issues associated with such breaking down (Shackeroff and Campbell 2007).

\section{CONCLUSIONS: WAYS FORWARD IN OCEAN CONSERVATION}

Our intention here is not to reject SBS altogether, but to suggest ways in which its contributions to improved ocean conservation might be enhanced. We suggest this can be accomplished through an expanded discussion of SBS, and its assumptions and prescriptions.

First, although the potential for interdisciplinary work is a strength of SBS, it is as yet unrealized. A wider array of social sciences and humanities researchers, and of research epistemologies, needs to be engaged in SBS and related projects in marine historical ecology. History and economics have informed SBS (either in describing baselines or informing solutions), but to a certain extent this work has reinforced the vision of oceans as biological or bioeconomic spaces, rather than, for example, social or political spaces (e.g., Steinberg 1999,2001 , St. Martin 2001). There is a wealth of information on human interactions with marine systems that is not currently captured (or even acknowledged) in SBS. Such wealth is illustrated in Bolster's (2006) description of marine environmental history:

We need to better understand many things: how different groups of people made 
themselves in the context of marine environments, how race, class, fashion, and geo-politics influenced the exploitation and conservation of marine resources, how individual and community identities (and economies) changed as a function of the availability of marine resources, how technological innovation frequently masked declining catches, how fishermen's knowledge of localized depletions accumulated in the past, how public policy debates revealed historically specific values associated with the ocean, how collaboration between (and then antagonism among) fishermen and scientists affected marine environments, how faith in the certainty of marine science waxed and waned, how different cultures perceived the ocean at specific times, and -when possible-how past marine environments looked in terms of abundance and distribution of important species. (Bolster 2006: 571-572.)

Although Bolster poses these questions as ones of historical interest, they can be recast in the present. We need to better understand many of these things now, and how they will play out as we move from describing the past to charting the future. To provide just one example, Aswani and Hamilton (2004) illustrate how an understanding of local marine tenure regimes and attitudes toward management in the Western Solomon Islands can (and should) be used to guide conservation interventions and predict their success.

Broader interdisciplinary collaboration will enhance the analysis of both problems and potential solutions, and may also help avoid the divide that has arisen in terrestrial conservation, where interactions between social and natural scientists have been characterized as a "dialog of the deaf" (Agrawal and Ostrom 2006). The impasse is attributed to both groups: natural scientists who are hostile and resistant to critiques of their efforts, and social scientists who, having delivered such critiques, fail to engage in constructive policy reform (Redford et al. 2006). Although there are hints that such divides could emerge in the marine realm [e.g., Pitcher (2005) dismisses as uniformed the critiques of SBS by unnamed social scientists], we hope that wider, earlier engagement of social and natural scientists can put marine research and conservation on a more productive trajectory.
The second area for broadened engagement is within ecology itself, specifically with resilience and complex system theories. Resilience theory treats ecosystems as complex and adaptive, characterized by uncertainty and change, and having multiple stable states (Holling 1973, Folke 2006). Whereas resilience theory originally focused on biological aspects of ecosystems, it has increasingly included human dimensions. Resilience theory now considers the dynamics of people to be inseparable from ecosystems: that is, humans and nature are coupled and coevolving in socialecological systems (SES) (Berkes and Folke 1998, Berkes et al. 2003). Resilience and SES draw from many disciplines across social and natural sciences and see diverse knowledge systems, including indigenous, local, and fisher perspectives, as central to understanding SES dynamics (Berkes et al. 2003, Folke 2004, 2006, Walker et al. 2006). These features have implications not only for how we assess past (and current) conditions, but for how we identify and engage relevant stakeholders in particular contexts. For example, St. Martin's (2005b) mapping of trip data by fishers in New England reveals a peopled seascape and suggests where, how, and who should be involved in efforts to manage related fisheries. Rather than asking people to participate in an SBS-defined vision of conservation, we should be thinking of how socialecological systems work and structuring participation in related and appropriate ways.

Similar to SBS, resilience theory recognizes degradation of marine ecosystems (e.g., Folke et al. 2004). However, in contrast to SBS's call for a return to baseline conditions, resilience asks how to strengthen the capacity of ecosystems to support social and economic development and sustain desirable pathways and ecosystem states in the face of continuous change (Folke et al. 2002, Gunderson and Holling 2002). For example, Wilson (2006) discusses the problem of mismatch between human behavior and regulating institutions and ocean ecosystems. Although he shares the concern of SBS writers with declining fish stocks and species-based management, his prescriptions are quite different, arguing for the necessity of multi-scale, spatially nested management subsystems that match ecosystem characteristics, and for governance and rights regimes that allow for locally based learning and adaptation. Wilson's argument demonstrates an important strength of an SES approach; governance is a part of the SES rather than an external 
institutional structure imposed on an ecological system.

The coming together of resilience theory and marine historical ecology will be no small task; the former emphasizes the future and the latter the past, and their conceptual models of ecosystems, specifically their differing commitments to baselines, may in the end be incommensurable. However, we argue that the benefits of a partnership between SES/resilience theory and marine historical ecology could cut both ways; until now, research on marine SESs has paid little attention to history. For example, most studies in SES address resilience following perturbations (e.g., coral reefs: Hughes et al. 2005; fisheries: Steele 1998, Robards and Greenberg 2007; natural disasters: Adger et al. 2005). There are some examples of using resilience to understand the historical context of marine SESs (e.g., Acheson 1997, Huntington 2000, Berkes and Folke 2002), but historical ecology is referenced in resilience literature (e.g., Hughes et al. 2005: 381) more often than it is actively pursued. We suggest that a resilience-oriented treatment of marine historical ecology would provide a more nuanced analysis of past social-ecological (rather than "natural") systems, and a more historically contextualized analysis of present SESs and their potential futures.

The third area for engagement is with resource users themselves, e.g., fishers, who can contribute to the discussion of past and future SESs as "experiencedbased experts" (Collins and Evans 2002) with valuable knowledge of the resources they rely on and considerable stakes in their management (Johannes et al. 2000, Berkes 2003). Although there is the problem of extension (i.e., determining who has the experience to warrant inclusion in the group), this kind of engagement is necessary. We do not mean to romanticize resource users, who may face a variety of pressures that push and pull them toward unsustainable resource use. Neither do we adopt an additive perspective on knowledge, where scientific knowledge plus local knowledge equals complete knowledge; they sometimes represent radically different ways of knowing and may be, at some levels, incommensurable. But excluding resource users (because of their practices, the problems of accounting for what they know and how they know it, or any other reason) is neither just nor, ultimately, practical. Indeed, an SES perspective makes their inclusion necessary (Wilson 2006).

We believe that expanding SBS and related work in marine historical ecology to be more broadly interdisciplinary, to engage with resilience and SES theory, and to engage with resource users will achieve two things. First, it will improve our understanding of marine social-ecological systems as they existed at various times in the past. That is, the scientific work of marine historical ecology will be enhanced. Second, it may facilitate a more direct recognition of the value judgments inherent in deciding both what past states are most desirable (and to whom) and if, how, and why we might try to recreate these in the future. This recognition is critical. Ultimately, when marine historical ecologists move from describing past baselines to advising both that they should be reestablished and how this should be accomplished, they move from the realm of science into that of advocacy. Policy advocacy by scientists - their explicit or implicit statement of preference for a particular policy or class of policies (Lackey 2007) — has been widely debated by scientists themselves (e.g., see issues 21 (1) and 10(3) of Conservation Biology). There are arguments both for and against, and we will not resolve such debates here. However, "stealth policy advocacy" (Lackey 2007), where policy preferences are implicit in the science instead of debated outside of it, should be avoided. Just as we argue that there is nothing "natural" or self-evident about past ecological baselines, marine historical ecology is not the "natural" authority for determining the direction of oceans policy. This is not to say that marine historical ecologists have no place at the negotiating table; rather, having provided the information obtained via their scientific expertise, they come to that table as citizens, where their policy preferences are one set considered among many others.

Responses to this article can be read online at: http://www.ecologyandsociety.org/voll4/iss 1/art14/ responses/

\section{Acknowledgments:}

We would like to think our friends and colleagues who participate in an interdisciplinary reading group at the Duke University Marine Lab, where the idea for this paper first took hold. Matthew Godfrey, Jack Frazier, and Kevin St. Martin provided feedback on at various stages in the manuscript's production. 


\section{LITERATURE CITED}

Acheson, J. M. 1997. The politics of managing the Maine lobster industry: 1860 to the present. Human Ecology 25(1):3-27.

Adams, W. M. 2007. Thinking like a human: social science and the two cultures problem. Oryx $\mathbf{4 1}$ (3):275-276.

Adger, W. N., T. P. Hughes, C. Folke, S. R. Carpenter, and J. Rockstrom. 2005. Socialecological resilience to coastal disasters. Science 309(5737):1036-1039.

Agrawal, A., and E. Ostrom. 2006. Political science and conservation biology: a dialogue of the deaf? Conservation Biology 20:681-682.

Aswani, S. and R. J. Hamilton. 2004. Integrating indigenous ecological knowledge and customary sea tenure with marine and social science for conservation of bumphead parrotfish (Bolbometopon muricatum) in Roviana Lagoon, Solomon Islands. Environmental Conservation 31(1):69-83.

Balé, W. 1998. Advances in historical ecology. Columbia University Press, New York, New York, USA.

Baum, J. K., and R. A. Myers. 2004. Shifting baselines and the decline of pelagic sharks in the Gulf of Mexico. Ecology Letters 7:135-145.

Berkes, F. 2003. Alternatives to conventional management: lessons from small-scale fisheries. Environments 31(1):5-19.

Berkes, F., J. Colding, and C. Folke. 2003. Navigating social-ecological systems: building resilience for complexity and change. Cambridge University Press, Cambridge, UK.

Berkes, F., and C. Folke. 1998. Linking social and ecological systems: management practices and social mechanisms for building resistance. Cambridge University Press, Cambridge, UK.

- 2002. Back to the future: ecosystem dynamics and local knowledge. Pages 121-146 in L. H. Gunderson and C. S. Holling, editors. Panarchy: understanding transformations in human and natural systems. Island Press, Washington, D.C., USA.
Bjorndal, K. A. 1982. The consequences of herbivory for the life history pattern of the Caribbean green turtle. Pages 111-116 in K. A. Bjorndal, editor. Biology and conservation of sea turtles. Smithsonian Institute Press, Washington, D. C., USA.

Bjorndal, K. A., and A. B. Bolten. 2003. From ghosts to key species: restoring sea turtle populations to fulfill their ecological roles. Marine Turtle Newsletter 100:16-21.

Bjorndal, K. A., A. B. Bolten, and M. Y. Chaloupka. 2000. Green turtle somatic growth model: evidence for density dependence. Ecological Applications 10(1):269-282.

Blockstein, D. E. 2002. How to lose your political virginity while keeping your scientific credibility. BioScience 52(1):91-96.

Bolster, W. J. 2006. Opportunities in marine environmental history. Environmental History 11 (3): 567-597.

Brockington, D., J. Igoe, and K. Schmidt-Soltau. 2006. Conservation, human rights, and poverty reduction. Conservation Biology 20(1):250-252.

Campbell, L. M. 2003. Challenges for interdisciplinary sea turtle research: perspectives of a social scientist. Marine Turtle Newsletter 100:2832.

2005. Overcoming obstacles to interdisciplinary research. Conservation Biology 19(2):574-577.

Canadian Science Advisory Secretariat. 2006. Stock assessment of northern (2J3KL) cod in 2006. Fisheries and Oceans Canada, Newfoundland and Labrador Region, St. John's, Newfoundland and Labrador, Canada.

Carlsson, L., and F. Berkes. 2005. Comanagement: concepts and methodological implications. Journal of Environmental Management 75(1):65-76.

Carscadden, J. E., W. A. Montevecchi, G. K. Davoren, and B. S. Nakashima. 2002. Trophic relationships among capelin (Mallotus villosus) and seabirds in a changing ecosystem. ICES Journal of Marine Science 59(5):1027-1033. 
Castree, N., and B. Braun. 2001. Social nature: theory, practice, and politics. Blackwell, Malden, Massachusetts, USA.

Chavez, F. P., J. P. Ryan, S. Lluch-Cota, and M. C. Niquen. 2003. From anchovies to sardines and back-multidecadal change in the Pacific Ocean. Science 299:217-221.

Christensen, V., S. Guénette, J. J. Heymans, C. J. Walters, R. Watson, D. Zeller, and D. Pauly. 2003. Hundred-year decline of North Atlantic predatory fishes. Fish and Fisheries 4(1):1-24.

Christie, P. 2004. MPAs as biological successes and social failures in Southeast Asia. Pages 155164 in J. B. Shipley, editor. Aquatic protected areas as fisheries management tools: design, use, and evaluation of these fully protected areas. American Fisheries Society, Bethesda, Maryland, USA.

Christie, P., B. J. McCay, M. L. Miller, C. Lowe, A. T. White, R. Stoffle, D. L. Fluharty, L. T. McManus, R. Chuenpagdee, C. Pomeroy, D. O. Suman, B. G. Blount, D. Huppert, R.-L. V. Eisma, E. Oracion, K. Lowry, and R. B. Pollnac. 2003. Toward developing a complete understanding: a social science research agenda for marine protected areas. Fisheries 28:22-26.

Collins, H. M., and R. Evans. 2002. The third wave of science studies: studies of expertise and experience. Social Studies of Science 32:235-296.

Cronon, W. 1995. Uncommon ground. W.W. Norton and Company, New York, New York, USA.

Crumley, C. L. 1994. Historical ecology: cultural knowledge and changing landscapes. School of American Research Press, Santa Fe, New Mexico, USA.

Folke, C. 2004. Traditional knowledge in socialecological systems. Ecology and Society 9(3): 7. [online] URL: http://www.ecologyandsociety.org/vol9/ iss $3 / \operatorname{art} 7 /$.

- 2006. Resilience: the emergence of a perspective for social-ecological systems analyses. Global Environmental Change-Human and Policy Dimensions 16(3):253-267.

Folke, C., S. Carpenter, T. Elmqvist, L. Gunderson, C. S. Holling, and B. Walker. 2002.
Resilience and sustainable development: building adaptive capacity in a world of transformations. Ambio 31(5):437-440.

Folke, C., S. Carpenter, B. Walker, M. Scheffer, T. Elmqvist, L. Gunderson, and C. S. Holling. 2004. Regime shifts, resilience, and biodiversity in ecosystem management. Annual Review of Ecology, Evolution, and Systemtics 35:557-581.

Food and Agriculture Organization (FAO). 2007. The state of world fisheries and aquaculture 2006. United Nations, FAO, Rome, Italy.

Frank, K. T., B. Petrie, J. S. Choi, and W. C. Leggett. 2005. Trophic cascades in a formerly coddominated ecosystem. Science 308(5728):16211623.

Gunderson, L., and C. Holling. 2002. Panarchy: understanding transformations in human and natural systems. Island Press, Washington, D.C., USA.

Holling, C. S. 1973. Resilience and stability of ecological systems. Annual Review of Ecology and Systematics 4:1-23.

Holling, C. S., F. Berkes, and C. Folke. 1998. Science, sustainability and resource management. Pages 342-362 in F. Berkes and C. Folke, editors. Linking social and ecological systems: management practices and social mechanisms for building resilience. Cambridge University Press, Cambridge, UK.

Hughes, T. P., D. R. Bellwood, C. Folke, R. S. Steneck, and J. Wilson. 2005. New paradigms for supporting the resilience of marine ecosystems. Trends in Ecology and Evolution 20(7):380-386.

Huntington, H. P. 2000. Traditional knowledge of the ecology of belugas, in Cook Inlet, Alaska. Marine Fisheries Review 62(3):134-140.

Jackson, J. B. C. 1997. Reefs since Columbus. Coral Reefs 16(Supplement):S23-S32.

Jackson, J. B. C. 2001. What was natural in the coastal oceans? Proceedings of the National Academy of Science 98(10):5411-5418.

Jackson, J. B. C., M. X. Kirby, W. H. Berger, K. A. Bjorndal, L. W. Botsford, B. J. Bourque, R. 
H. Bradbury, R. Cooke, J. Erlandson, J. A. Estes, T. P. Hughes, S. Kidwell, C. B. Lange, H. S. Lenihan, J. M. Pandolfi, C. H. Peterson, R. S. Steneck, M. J. Tegner, and R. R. Warner. 2001. Historical overfishing and the recent collapse of coastal ecosystems. Science 293(5530):629-638.

Jackson, S. E. 1995. The water is not empty: crosscultural issues in conceptualizing sea space. Australian Geographer 26(1):87-96.

Jentoft, S. 2006. Beyond fisheries management: the phronetic dimension. Marine Policy 30(6):671680.

Johannes, R. E., M. M. R. Freeman, and R. J. Hamilton. 2000. Ignore fishers' knowledge and miss the boat. Fish and Fisheries 1(3):257.

King, T. J. 2005. Crisis of meanings: divergent experiences and perceptions of the marine environment in Victoria, Australia. The Australian Journal of Anthropology 16(3):350-360.

Kirch, P. V., and T. L. Hunt. 1997. Historical ecology in the Pacific Islands: prehistoric and landscape change. Yale University Press, New Haven, Connecticut, USA.

Lackey, R. T. 2007. Science, scientists, and policy advocacy. Conservation Biology 21(1):12-17.

Leach, M., I. Scoones, and B. Wynne. 2005. Science and citizens: globalization and the challenge of engagement. Zed Books, London, UK.

Lélé, S., and R. B. Norgaard. 1996. Sustainability and the scientist's burden. Conservation Biology 10 (2):354-365.

Maurstad, A. 2000. To fish or not to fish: smallscale fishing and changing regulations of the cod fishery in northern Norway. Human Organization 59(1):37-47.

Olsson, P., C. Folke, and F. Berkes. 2004. Adaptive comanagement for building resilience in social-ecological systems. Environmental Management 34(1):75-90.

Pauly, D. 1995. Anecdotes and the shifting baseline syndrome of fisheries. Trends in Ecology and Evolution 10(10):430.
-. 2006. Unsustainable marine fisheries. Sustainable Development Law and Policy 7(1):10 12.

Pauly, D., V. Christensen, S. Guénette, T. J. Pitcher, U. R. Sumaila, C. J. Walters, R. Watson, and D. Zeller. 2002. Towards sustainability in world fisheries. Nature 418(6898):689-695.

Pauly, D., V. Christensen, and C. Walters. 2000. Ecopath, ecosim, and ecospace as tools for evaluating ecosystem impact of fisheries. ICES Journal of Marine Science 57:697-706.

Pinnegar, J. K. and G. H. Engelhard. 2008. The 'shifting baseline' phenomenon: a global perspective. Review of Fish Biology and Fisheries 18:1-16.

Pitcher, T. 2001. Fisheries managed to rebuild ecosystems? Reconstructing the past to salvage the future. Ecological Applications 11(2):601-617.

2005. Back-to-the-future: a fresh policy initiative for fisheries and a restoration ecology for ocean ecosystems. Philosophical Transactions of the Royal Society B 360:107-121.

Pitcher, T. J., and D. Pauly. 1998. Rebuilding ecosystems, not sustainability, as the proper goal of fishery management. Pages 311-325 in T. Pitcher, D. Pauly, and P. Hart. editors. Reinventing fisheries management. Kluwer, Dordrecht, The Netherlands.

Pollnac, R. B., and J. J. Poggie. 2006. Job satisfaction in the fishery in two southeast Alaskan towns. Human Organization 65:329-339.

Redclift, M. 1998. Dances with wolves? Interdisciplinary research on the global environment. Global Environmental Change 8(3):177-182.

Redford, K. H., J. G. Robinson, and W. M. Adams. 2006. Parks as shibboleths. Conservation Biology 20(1):1-2.

Robards, M. D., and J. A. Greenberg. 2007. Global constraints on rural fishing communities: whose resilience is it anyway? Fish and Fisheries 8(1):14-30.

Rosenberg, A. A., W. J. Bolster, K. E. Alexander, W. B. Leavenworth, A. B. Cooper, and M. G. McKenzie. 2005. The history of ocean resources: 
modeling cod biomass using historical records. Frontiers in Ecology and Environment 3(2):84-90.

Sánz-Arroyo, A., C. M. Roberts, J. Torre, M. Carino-Olvera. 2005. Rapidly shifting environmental baselines among fishers of the Gulf of California. Proceedings of the Royal Society of London B 272 (1575):1957-1962.

Scheffer, M., and S. R. Carpenter. 2003. Catastrophic regime shifts in ecosystems: linking theory to observation. Trends in Ecology and Evolution 18(12):648-656.

Shackeroff, J., and L. M. Campbell. 2007. Traditional ecological knowledge in conservation research: problems and prospects for their constructive engagement. Conservation and Society 5(3):343-360.

Steele, J. H. 1998. Regime shifts in marine ecosystems. Ecological Applications 8(1):S33S36.

Steinberg, P. E. 1999. The maritime mystique: sustainable development, capital mobility, and nostalgia in the world ocean. Environment and Planning D 17(4):403-426.

Steinberg, P. E. 2001. The social construction of the ocean. Cambridge University Press, Cambridge, UK.

St. Martin, K. 2001. Making space for community resource management in fisheries. Annals of the Association of American Geographers 91(1):122142.

- 2005a. Disrupting enclosure in New England fisheries. Capitalism, Nature, Socialism 16 (1):63-80.

- 2005b. Mapping economic diversity in the First World: the case of fisheries. Environment and Planning A 37:959-979.

Troëg, S., and E. Rankin. 2005. Long-term conservation efforts contribute to positive green turtle (Chelonia mydas) nesting trend at Tortuguero, Costa Rica. Biological Conservation 121:111-116.

van Sittert, L. 2005. The other seven tenths. Environmental History 10(1):106-109.
Walker, B. H., J. M. Anderies, A. P. Kinzig, and P. Ryan. 2006. Exploring resilience in socialecological systems through comparative studies and theory development: introduction to the special issue. Ecology and Society 11(1): 12. [online] URL: http://www.ecologyandsociety.org/vol11/iss1/art12/

Wilson, D. C., J. R. Nielsen, and P. Degnbol. 2003. The fisheries co-management experience: accomplishments, challenges and prospects. Kluwer, Dordrecht, The Netherlands.

Wilson, J. A. 2006. Matching social and ecological systems in complex ocean fisheries. Ecology and Society 11(1): 9. [online] URL: http://www.ecolog yandsociety.org/vol11/iss1/art9/.

Worm, B., E. B. Barbier, N. Beaumont, J. E. Duffy, C. Folke, B. S. Halpern, J. B. C. Jackson, H. K. Lotze, F. Micheli, S. R. Palumbi, E. Sala, K. A. Selkoe, J. J. Stachowicz, and R. Watson. 2006. Impacts of biodiversity loss on ocean ecosystem services. Science 314(5800):787-790. 